\section{THE CONSEQUENCIES OF SHARING ECONOMY ON OCCUPATIONAL SAFETY AND HEALTH}

Pauli Forma*. Keva, Helsinki, Finland

\subsection{6/oemed-2018-ICOHabstracts. 1464}

Introduction The object of the study is to clarify the effects of 'sharing economy' and 'platform economy' on occupational safety and health. The argument is that these megatrends challenge present ways to guarantee safety and health for workers. Our modern solution for occupational safety and health has been the welfare state. In this context, the government, the employers and the employees have had their own rights and responsibilities. However, the sharing economy and the platforms (such like Uber, Airbnb, TaskRabit etc.) as an essential part of it, challenge present ways to guarantee safety and health to the workers.

Methods Literature concerning the sharing economy and platform economy are reviewed and effects of these on occupational safety and health are clarified. Level of awereness concerning the risks caused by sharing economy and platforms in various countries in the field of occupational safety and health is discussed. Further steps which are needed are indentified.

Results There seem to be many reasons why risks for unemployment, occupational safety and health are rising in the context of sharing economy and platforms. First and foremost, sharing economy may increase uncertainty and unemployment in the working life. Second, there are many changes related to work. Second, platforms are not employers with their responsibilities. Third, employees lack collective power, Fourth, governments lack resources (tax base) and power (platforms are global) to guarantee health and safety. Of course, we have to remember that new technology may also help us to to provide safety and health.

Discussion The system which provides security and safety for the citizens is always connected to changes in economic and social context. Now, the balance of needs for safety and health and means to guarantee them is changing. In order to provide safety and health, we have to renew our strategies to provide them. It is evident that we should consider incentives for the platforms to introduce innovations in the field of safety and health. In addition, since the platforms are global, international co-operation is needed.

\section{INVESTIGATION AND ANALYSIS OF TINNITUS IN NOISE EXPOSED WORKERS}

Lu Bai*, Xiong He, Hongyan Yang, Fanghong Zhao, Rugang Wang. Beijing Centre for disease Prevention and Control, Beijing, China

\subsection{6/oemed-2018-ICOHabstracts. 1465}

Introduction Tinnitus leads to hearing loss, sleeping disorder, upset and affects normal life and job performance. It's a vicious circle. It is worse among noise exposed workers. The investigation was conducted in railway transport equipment manufacturing industry aiming on the cause, treatment, prognosis and impact of hearing level of tinnitus. Expecting to present advice and promote occupational health.
Methods A cross-sectional study was conducted among 1034 workers in face-to-face survey in Beijing in 2016. Substances included social statistics data, occupational history, past history and lifestyle. Data were analysed using SPSS21.0.

Result Tinnitus prevalence in the exposed group was $36.6 \%$, higher than that in the control group (18.8\%). In the exposed group tinnitus prevalence of workers without PPE was $41.7 \%$, higher than that of workers with PPE (36.2\%). Tinnitus prevalence of workers exposed to high dose was $54.0 \%$, higher than that of low dose $(34.7 \%)$. In both groups health concern rates were $83.7 \%$ and $91.1 \%$, while poor consultation rates were $15.8 \%$ and $7.2 \%$. No significant differences of prognosis were observed between two groups. In the exposed group hearing loss prevalence in workers with tinnitus was $67.9 \%$ higher than that of workers without tinnitus (49.8\%).

Discussion For noise exposed workers, without PPE and directly exposed to noise were main causes of tinnitus. A dose-effect relationship was observed. No evidence approved noise exposing could deteriorate the prognosis of tinnitus. Misunderstanding for the principle and efficacy of tinnitus treatments resulted in low consultation rate. Understanding of masking and retraining therapy help patients adapt to tinnitus. Other measures are necessary such as healthy habits, avoiding overwork and ear heath care. There is cause-and-effect between tinnitus and hearing loss. It is recommended that employer should supervise strictly, provide double protection for employee exposed to high-dose-noise and restrict exposing time on the basis of national standards.

\section{THE ANALYSIS OF INDIVIDUAL FACTORS AND NOISE INDUCED HEARING LOSS}

Lu Bai* ${ }^{*}$ Xiong He, Hongyan Yang, Fanghong Zhao, Rugang Wang. Beijing Centre for disease Prevention and Control, Beijing, China

\subsection{6/oemed-2018-ICOHabstracts.1466}

Introduction Noise exposing is the main reason of NIHL. But even exposed to same noise and time effects are totally different, some workers have normal hearing level, some have minor loss and other may have severe loss. So NIHL is complicated and related to not only working environment but also individual and genetic factors. Individual factors include specific character, behaviour and habits. The study discussed individual factors interfering with NIHL and presented advice. Methods A retrospective cohort study was conducted among noise-exposed-workers in railway-transport-equipment-manufacturing-industry in Beijing in 2016. Occupational history and individual factors were collected. Data were analysed using SPSS with binary logistic regression(backward elimination).

Result Regression equation was $\operatorname{Logit}(\mathrm{P})=-2.349-1.349$ sex +2.700 age (1) +1.994 age (2) +1.291 age (3) +0.736 infectious-disease +0.086 nonce-BMI. (likelihood-ratio-test, $\mathrm{X}^{2}=4.713 \mathrm{P}<0.05$ ).

age (1) $\mathrm{p}=0.000 \mathrm{OR}=14.876$ 95\% CI: $5.629 \sim 39.319$

age (2) $\mathrm{p}=0.000 \mathrm{OR}=7.346$ 95\% CI: $4.222 \sim 12.780$

age (3) $\mathrm{p}=0.000$ OR $=3.63895 \% \mathrm{CI}: 2.056 \sim 6.436$

sex, $\mathrm{p}=0.000 ; \mathrm{OR}=0.260 ; 95 \% \mathrm{CI}: 0.137 \sim 0.492$

infectious-disease $\quad \mathrm{p}=0.003 \quad \mathrm{OR}=2.087 \quad 95 \% \mathrm{CI}$ :

$1.291 \sim 3.375$

nonce-BMI $\mathrm{p}=0.011 \mathrm{OR}=1.09095 \% \mathrm{CI}: 1.020 \sim 1.165$. 